\title{
A Front end Switched Rectifier DC Source for Neutral Point Balancing of A NPC Three-Level Inverter for The Full Modulation Range
}

\author{
K. Siva kumar ${ }^{1}$, Sukumar De ${ }^{1}$, K.Gopakumar ${ }^{1}$, Gopal Mondal ${ }^{1}$, Keith Corzine ${ }^{2}$ \\ ${ }^{1}$ CEDT, Indian Institute of Science, Bangalore, India; ${ }^{2}$ Department of EE, University of Missouri, Rolla, USA \\ kgopa@cedt.iisc.ernet.in, \\ Keitth@Corzine.net
}

\begin{abstract}
A switched DC voltage three level NPC is proposed in this paper to eliminate capacitor balancing problems in conventional three-level Neutral Point Clamped (NPC) inverter. The proposed configuration requires only one DC link with a voltage $V_{d c} / 2$, where $V_{d c}$ is the DC link voltage in a conventional NPC inverter. To get rated DC link voltage $\left(V_{d c}\right)$, the voltage source is alternately connected in parallel to one of the two series capacitors using two switches and two diodes with device voltage rating of $V_{d c} / 2$. The frequency at which the voltage source is switched is independent and will not affect the operation of NPC inverter. The switched voltage source in this configuration balances the capacitors automatically. The proposed configuration can also be used as a conventional two level inverter in lower modulation range, thereby increases the reliability of the drive system. A space vector based PWM scheme is used to verify this proposed topology.
\end{abstract}

\section{INTRODUCTION}

Multilevel inverters are becoming popular for high power industrial drives. The major advantages of multilevel inverters are improved harmonic performance, reduced stress on the switches and reduced electromagnetic interference (EMI) emission. Various multi-level inverter topologies were proposed in [1-9]. Three level NPC inverter is proposed [1] by Nabae et al. for the first time. But the NPC inverter has a major disadvantage that there will be voltage unbalance in DCCapacitors. The H-bridge topology proposed in reference [2, 3] does not have the voltage unbalance problem, but it requires three isolated DC power supplies. The open-end winding induction motor drive topology proposed in [4] and cascading two two-level inverters topology proposed in [5] eliminate this problem but require two power supplies. Dual two-level inverter scheme for an open-end winding induction motor drive with a single DC power supply is proposed in [6] but it requires four extra four-quadrant switches. A modification of the conventional NPC inverter is suggested in [7], in which a capacitor is added across the neutral clamping diodes to ensure dynamic balancing of the DC-bus capacitors. But this method does not eliminate the neutral-point fluctuations completely. A generalized multi-level inverter topology suggested in [8]. But this topology requires individual capacitor banks for each phase. Three level PWM Switched voltage source Inverter proposed in [9], requires one extra capacitor bank for each phase and the modulation index is restricted by the inductance value. In [11] a DC link voltage balancing is proposed using dc-dc converter technology on the DC link side. This needs extra inductors and components, making the power bus assembly, very complicated. A DC link capacitor balancing using PWM based virtual vectors is reported in [12]. But the modulating signal generation in all the modulation range and the PWM control with DC link balancing in the over modulation region is not properly addressed. The DC link balancing for diode clamped inverter is possible, for all the modulation range, with back-to-back inverter structure [13]. But this will increase the power circuit complexity and the cost. The redundant two-level inverter structure present in the conventional NPC-three-level inverter is effectively utilised for DC link capacitor balancing in [14], in the lower modulation range. But the neutral point balancing with DC link voltage control, is not addressed for the higher modulation ranges in [14].

In this paper, a power circuit configuration of switched rectifier voltage source for a NPC three-level inverter is proposed. The DC link Voltage required is half compared to the conventional NPC inverter. In the lower modulation $(\mathrm{M}<0.433)$ range NPC inverter can be operated as a two level inverter, by clamping the voltage source across the bottom capacitor or to the top capacitor. This will also increase the reliability of the drive system, and also the capacitor balancing problem in lower modulation indices, without resorting to redundant switching state selection, in PWM control. In the higher modulation range the voltage fluctuations of the neutral point are eliminated by switching the voltage source between two capacitors. Only two switches and two diodes are required additionally for achieving this. The switching of the voltage source between the two capacitors will not affect the operation of the NPC inverter.

\section{CONVENTIONAL THREE-LEVEL NPC INVERTER}

The conventional three-level NPC inverter shown in Fig.1 has 27 switching states, and the switching states are presented in Fig.2. These 27 switching states are classified into three groups $\mathrm{A}, \mathrm{B}$ and $\mathrm{C}$, as shown in Table I. When switching states in Group A are used in a three level NPC inverter, the load is connected between terminal $\mathrm{P}$ and $\mathrm{N}$ or to either one. In this case, the current through the capacitors will be equal and there will not be any voltage unbalance problems, in capacitors $(\mathrm{C} 1$ and C2, Fig.1). When switching states in Group-B are used for 
inverter control, the neutral point is connected along with the terminals $\mathrm{P}$ and $\mathrm{N}$ to the output load. So the currents flowing through the capacitors will be different and causes voltage unbalance. When switching states in Group-C are used the load is connected between the terminal $\mathrm{P}$ and the neutral point or terminal $\mathrm{N}$ and the neutral point. Here the capacitor currents are equal, but the flow is in opposite direction. In this condition, when one capacitor charges, the other capacitor discharges at the same rate. This can lead to unbalance in voltage across the capacitors $\mathrm{C} 1$ and $\mathrm{C} 2$.

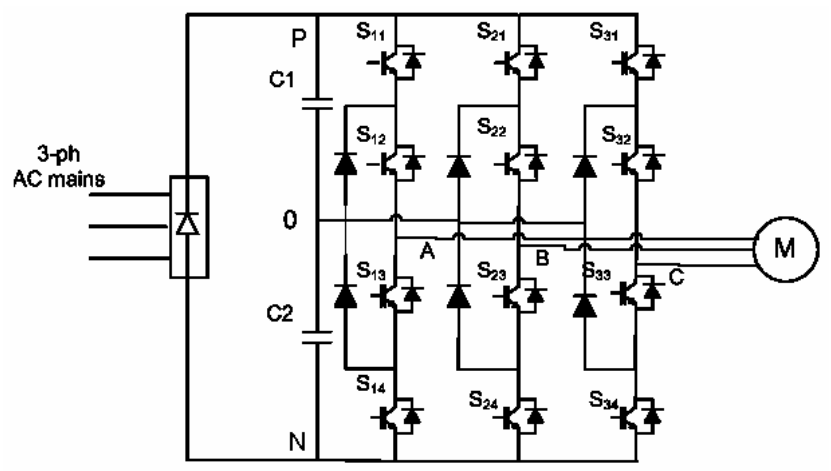

Fig.1. conventional three-level NPC inverter

TABLE I

SWITCHING STATES GROUPS BASED ON THE DC CAPACITOR CHARGING AND DISCHARGING

\begin{tabular}{|l|l|}
\hline Group-A & $000,---,+++,+--,++-,-+-,-++,--+,+-+$ \\
\hline Group-B & $+0-, 0+-,-+0,-0+, 0-+,+-0$ \\
\hline Group-C & $00+, 0+0,0++,+0+,+00,++0,0--, 00-,-0-,-00,--0,0-0$ \\
\hline
\end{tabular}

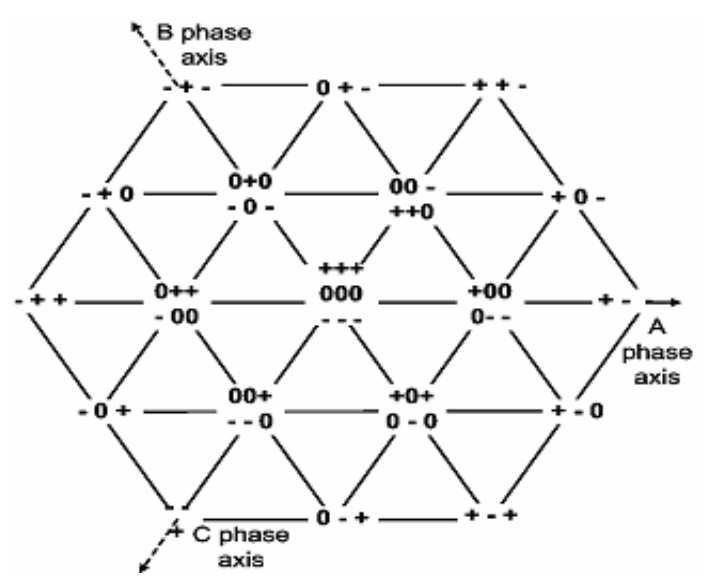

Fig.2. Space-vector combinations for three level NPC

\section{Proposed Switched Voltage source Three LeVel NPC INVERTER}

Fig.3. shows the proposed switched voltage source three level NPC inverter configuration. In the proposed topology, only one active voltage source of $\mathrm{V}_{\mathrm{dc}} / 2$ is used. The rated DC link voltage can be obtained by switching the voltage source $\left(\mathrm{V}_{\mathrm{dc}} / 2\right)$ between the top $(\mathrm{C} 1)$ and bottom $(\mathrm{C} 2)$ capacitors with a duty ratio of 0.5 . Capacitors are charging to $\mathrm{V}_{\mathrm{dc}} / 2$ with a constant frequency irrespective of the load currents. So the load current flowing through the capacitors will not create any neutral point fluctuations. Here the diode bridge rectifier and filter capacitor (C3) is used as an input voltage source. To switch the voltage source between the capacitors $\mathrm{C} 1$ and $\mathrm{C} 2$, extra two switches and two diodes are required, as shown in the Fig.3. The ratings of these devices are also, $V_{\mathrm{dc}} / 2$ as in the case of the NPC inverter switches of Fig.1

From Fig. 3 it can be seen that when the switch $\mathrm{S}_{1}$ is $\mathrm{ON}$, the voltage difference between the source and capacitor $\mathrm{C} 1$ will make the diode D1 forward biased, and connects the voltage source in parallel to the capacitor $\mathrm{C} 1$ as shown in Fig. 4(a). The voltage across the $\mathrm{S} 2$ and $\mathrm{D} 2$ is $\mathrm{V}_{\mathrm{dc}} / 2$. When the switch $\mathrm{S} 2$ is turned $\mathrm{ON}$, the voltage difference between the source and capacitor C2 will make the diode D2 forward biased, and connects the voltage source in parallel to the capacitor $\mathrm{C} 2$, as shown in Fig.4(b). In both the cases, the capacitor C3 is parallel to $\mathrm{C} 1$ or $\mathrm{C} 2$, so a low value of capacitor for $\mathrm{C} 3$ will not alter the original $\mathrm{C} 1$ and $\mathrm{C} 2$ values of the NPC inverter of Fig.1.In the present study $220 \mu \mathrm{F}$ is used for $\mathrm{C} 3$ and $2200 \mu \mathrm{F}$ is used for $\mathrm{C} 1$ and $\mathrm{C} 2$.

In the proposed topology extra switches are used to maintain the rated DC link voltage across the two capacitors. These extra switches and the capacitor C3 will not affect the inverter switching operation. So the inverter can be operated like a conventional three level NPC inverter.

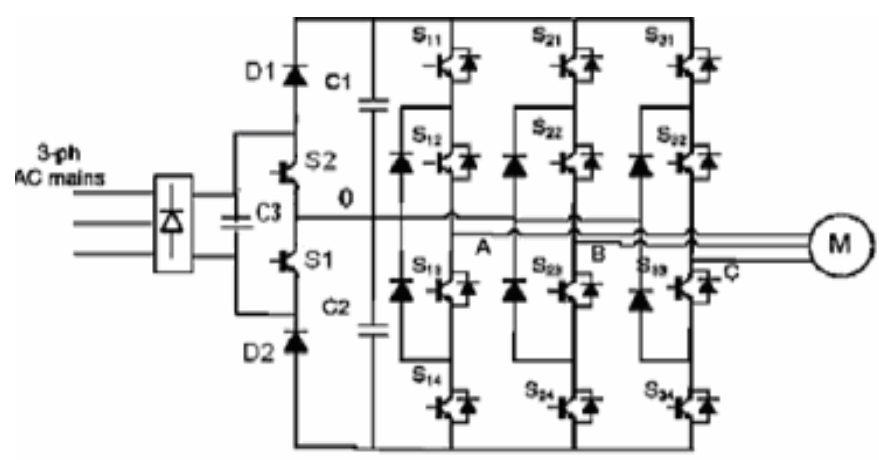

Fig.3. proposed Switched Voltage Source Three level NPC Inverter

\section{The DC Link Voltage Control}

For the modulation index less than 0.433 the reference voltage space vector will be in the inner hexagon ( Fig.2) and it indicates that the inverter will switch with the switching states shown in the group-C, as shown in Table-1 and the zero switching states. In this operating region, for the conventional NPC, the capacitor balancing problem is serious. Here, one capacitor (either the top or the bottom depending on the active inverter switching state) will be discharging with the full load current, and the other gets charged. This can lead to large 
neutral point fluctuations. This problem is completely eliminated in the proposed topology by operating NPC as a two-level inverter. By switching on S2 the voltage source will be parallel to the capacitor C2 ( Fig.4 (b)) for the active inverter switching states, $0--, 00-,-0-,-00,--0$, and $0-0$. the zero states will not contribute to the DC link capacitor voltage fluctuations. Similarly by selecting the redundant states $(+00$, $++0,0+0,0++, 00+)$, the upper inverter with the DC link capacitor $\mathrm{C} 1$ can also be used as conventional two-level inverter.

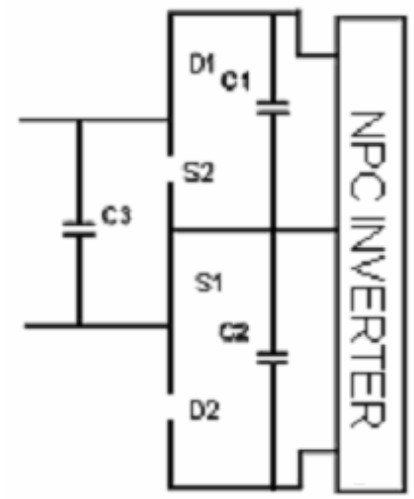

(a)

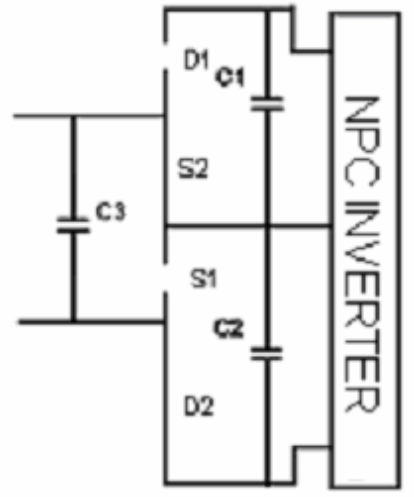

(b)
Fig.4.(a) Source capacitor $\mathrm{C} 3$ is parallel to the Capacitor $\mathrm{C} 1$ when $\mathrm{S} 1$ is ON. (b). Source capacitor C3 is parallel to the capacitor C2 when S2 is ON

For the modulation index more than 0.433 the reference space vector will cross the inner hexagon and the inverter has to operate as a three level inverter. The rated DC link voltage across the NPC inverter can be maintained by switching the Switches $S_{1}$ and $S_{2}$ at constant frequency with a duty ratio of 0.5 as mentioned earlier. The minimum switching frequency (fs) of the switches S1 and S2 for an ' $n$ ' pulse rectifier can be determined as follows.

$\mathrm{fsw}=\mathrm{N}^{*}((\mathrm{n} * \mathrm{fl}) / 2)$

Where

fsw $=$ Switching frequency of extra switches

f1 = Supply frequency

$\mathrm{N}=$ odd integer

Taking the supply frequency of $50 \mathrm{~Hz}$, for a six pulse rectifier the minimum switching frequency of the extra switches ( $\mathrm{S} 1$ and $\mathrm{S} 2)$ is $150 \mathrm{~Hz}(\mathrm{~N}=1$ in eqn (1)). From the Fig. 5 (a) it can be observed that the capacitor $(\mathrm{C} 1$ or $\mathrm{C} 2)$ is connected to the diode bridge rectifier in alternate peaks, so that each capacitor will charge to the peck value of the input voltage. Loss of synchronisation between the gating pulses and the diode bridge rectifier output will not cause any serious problem because of the symmetry.

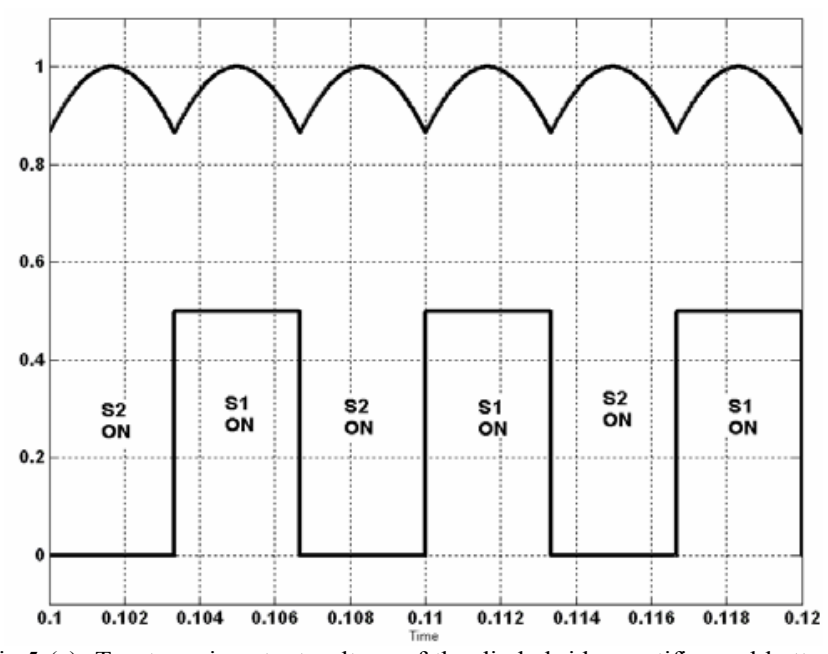

Fig.5 (a): Top trace is output voltage of the diode bridge rectifier and bottom trace is gating pulse of the extra switch $\mathrm{S}_{1}$ (Scale $\mathrm{X}$ axis: $\left.2 \mathrm{~ms} / \mathrm{div}\right)$.

If $\mathrm{N}$ is 2 (even integer) the capacitors $\mathrm{C}_{1}$ and $\mathrm{C}_{2}$ will charge unequally. From the Fig.5 (b) it can be observed that one of the capacitor is always connected to the diode bridge rectifier, during the input ripple peak. So one capacitor will charge to the input peak value and other capacitor will charge to less than the peak value. This will result in constant voltage difference between the two capacitors $\mathrm{C}_{1}$ and $\mathrm{C}_{2}$.

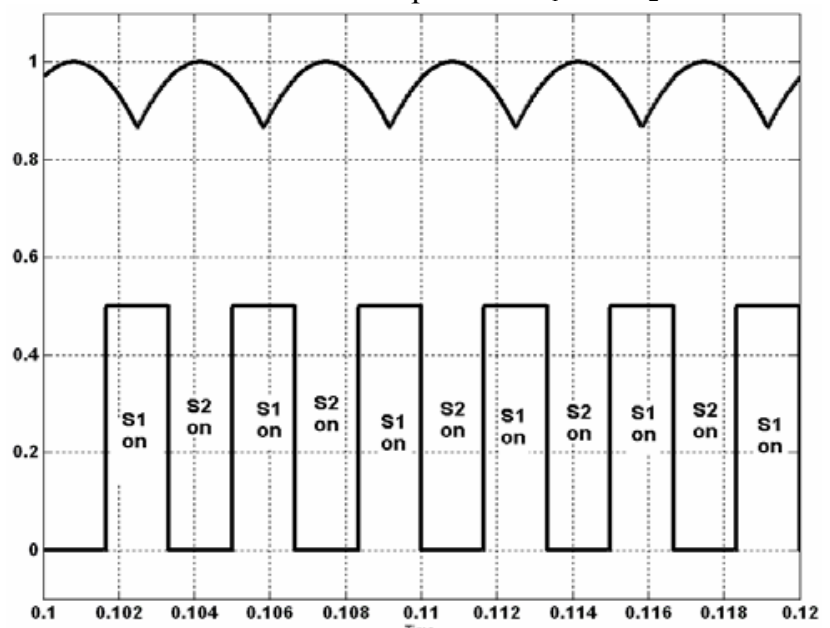

Fig.5 (b): Top trace is output voltage of the diode bridge rectifier and bottom trace is gating pulse of the extra switch $\mathrm{S}_{1} \mathrm{X}$ axis: $2 \mathrm{~ms} / \mathrm{div}$ ), fsw $=300 \mathrm{~Hz}$

When the input DC source is switched between $\mathrm{C} 1$ and $\mathrm{C} 2$, using the switches $\mathrm{S} 1$ and $\mathrm{S} 2$, there can be sudden interruption of the rectifier current due to the dead time between $\mathrm{S} 1$ and $\mathrm{S} 2$ ( typically $5 \mu \mathrm{sec})$. During this period the capacitor C3 is provided to give the current path to take care of the leakage inductance due to the front end rectifier transformer and due to line inductance. The value of the capacitor $C_{3}$ will be low, compared to $\mathrm{C} 1$ and $\mathrm{C} 2$, because the dead time is small, and can be approximately determined from (2). 


$$
C=\frac{(i * \Delta T)}{\Delta V}
$$

Where

$\mathrm{i}=$ rectifier output current

$\Delta \mathrm{T}=$ Dead time between the switches $\mathrm{S} 1$ and $\mathrm{S} 2$

$\Delta \mathrm{V}=$ voltage ripple in capacitor $\mathrm{C}_{3}$ (typically $5 \%$ of $\mathrm{Vdc}$ )

\section{EXPERIMENTAL RESULTS}

The proposed topology is experimentally verified on a $1 \mathrm{KW}$ three phase induction motor drive. It is tested for the entire speed range by using V/f control. Space vector PWM scheme [10] is used to generate the switching pulses for the three level NPC inverter. The inverter switching frequency is $1 \mathrm{KHz}$ and the switches S1 and S2 used for DC link voltage control are switched at a constant frequency of $750 \mathrm{~Hz}$. The value of capacitor $\mathrm{C} 3$ is $220 \mu \mathrm{F}$. the gating signals are generated using TMS320 F 2812 DSP and GAL22V10B platforms.

The experimental results for modulation index 0.4 (i.e. $20 \mathrm{~Hz}$ operation) are presented in Fig.6. Fig.6 (a) shows Pole voltage and Phase current. Fig.6(b) shows (upper trace) the three capacitor $\left(\mathrm{C}_{1}, \mathrm{C} 2\right.$ and $\left.\mathrm{C}_{3}\right)$ voltages and the charging current of $\mathrm{C} 1$ from the switched rectifier. Here the inverter is operated as a conventional NPC three level inverter. It can be observed from Fig.6(b) that the proposed switched rectifier is capable of maintaining the DC link capacitor balance. It can also be noted that the $\mathrm{C} 1$ capacitor charging current pulses (bottom trace Fig.6 (b)) are of unequal amplitudes due to the front end rectifier switching with $750 \mathrm{~Hz}$. But, in lower modulation indices, by appropriately clamping the $\mathrm{DC}$ source to $\mathrm{C} 1$ or $\mathrm{C} 2$, depending on the inverter switching state, the capacitor charging current will be similar to that of a front rectifier charging the output DC capacitor, similar to that of a diode bridge rectifier charging the DC link capacitor. Fig.6(c) shows the phase voltage, voltage across the switch $S_{1}$, phase current and the charging current $\mathrm{C} 1$ through the switch $\mathrm{S} 2$ from top to bottom trace. From the waveform it can be observed that the front end rectifier switches (S1 and S2) are switching

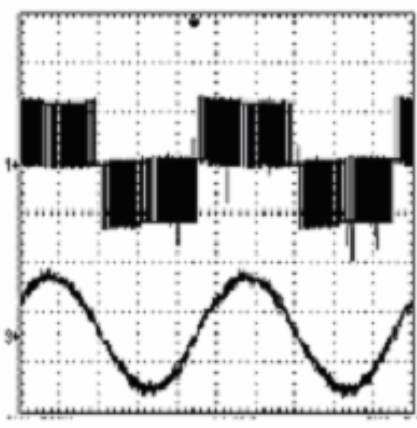

(a)

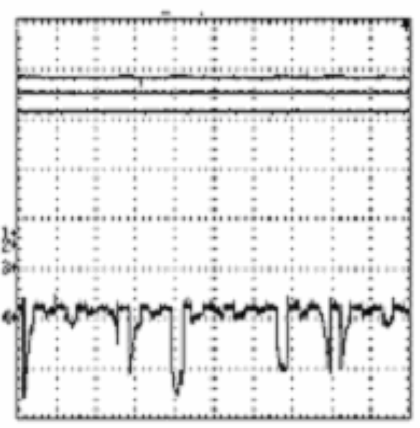

(b)
Fig.6(a)Top trace is Pole voltage and bottom trace is phase current at $\mathrm{M}=0.4$ [ $\mathrm{X}$-axis $10 \mathrm{~ms} / \mathrm{div} \mathrm{Y}$-axis $50 \mathrm{~V} / \mathrm{div}$ and $0.3 \mathrm{~A} / \mathrm{div}$. (b) Top three traces are Capacitor Voltages and bottom trace is Switched rectifier current to $\mathrm{C} 1$ [X- axis $2.5 \mathrm{~ms} / \mathrm{div}, \mathrm{Y}$-axis $20 \mathrm{~V} / \mathrm{div}$ and $1 \mathrm{~A} / \mathrm{div}]$. at $750 \mathrm{~Hz}$ for charging the NPC DC link capacitors. As mentioned before, the present scheme is also run as a conventional two- level inverter in lower modulation indices, by clamping the rectifier across C2 of the NPC three-level inverter and appropriate switching states are only used for the present operation. The phase voltage, pole voltage, line voltage and phase current are presented in fig.6 (d). This two level operation will completely eliminate the capacitor balancing problem (neutral point voltage fluctuations), in lower modulation indices.

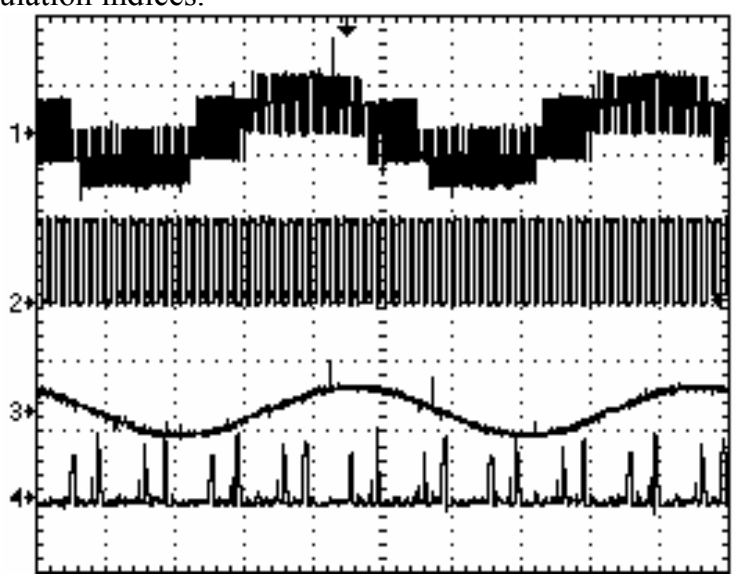

Fig. 6(c) Top trace is phase voltage, Second trace is voltage across the switch $\mathrm{S} 1$, Third trace is phase current and bottom trace is Switched rectifier current to $\mathrm{C} 1$ at $\mathrm{M}=0.4$. [X-axis $10 \mathrm{~ms} / \mathrm{div}, \mathrm{Y}$-axis $50 \mathrm{~V} / \mathrm{div}$ and $1 \mathrm{~A} / \mathrm{div}]$.

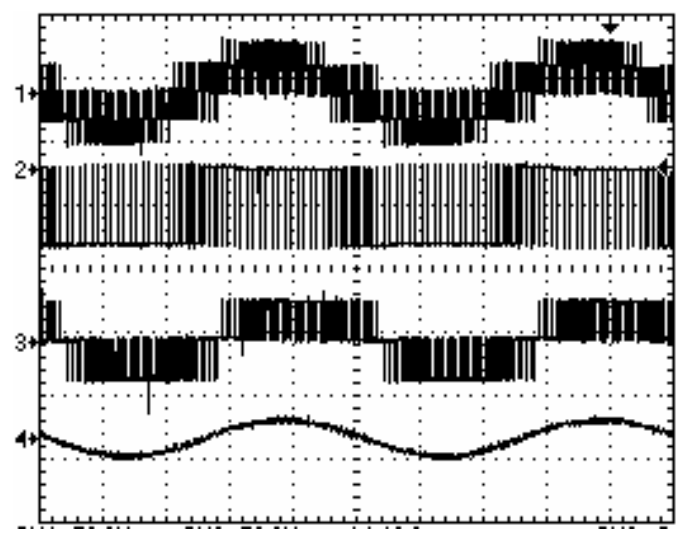

Fig. 6(d) Top trace is phase voltage (Van) [Y-axis 50V/div], second trace is Pole voltage(Vao) [Y-axis $50 \mathrm{~V} / \mathrm{div}]$, third trace is line voltage (Vab)[Y-axis $100 \mathrm{~V} / \mathrm{div}$ ] and bottom trace is Phase current [Y-axis $1 \mathrm{~A} / \operatorname{div}$ and $\mathrm{X}$-axis $10 \mathrm{~ms} / \mathrm{div}]$

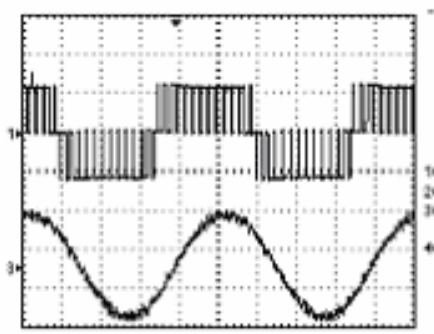

(a)

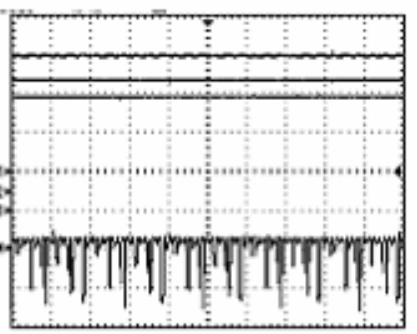

(b)
Fig.7(a) Top trace is pole voltage and bottom trace is phase current at $\mathrm{M}=0.8$ [ $\mathrm{X}$-axis $10 \mathrm{~ms} /$ div $\mathrm{Y}$-axis $50 \mathrm{~V} / \mathrm{div}$ and $0.3 \mathrm{~A} / \mathrm{div}]$. (b) Capacitor Voltages and Switch current [X-axis $10 \mathrm{~ms} / \mathrm{div}, \mathrm{Y}$-axis $20 \mathrm{~V} / \mathrm{div}$ and $1 \mathrm{~A} / \mathrm{div}]$. 
The pole voltage and phase current for modulation index 0.8 (i.e. $40 \mathrm{~Hz}$ operation) are presented in Fig. 7(a). The capacitor voltages and switch currents are presented in Fig.7(b). Fig.7(c) shows the phase voltage, voltage across the switch S1, phase current and Switch (S1) current.

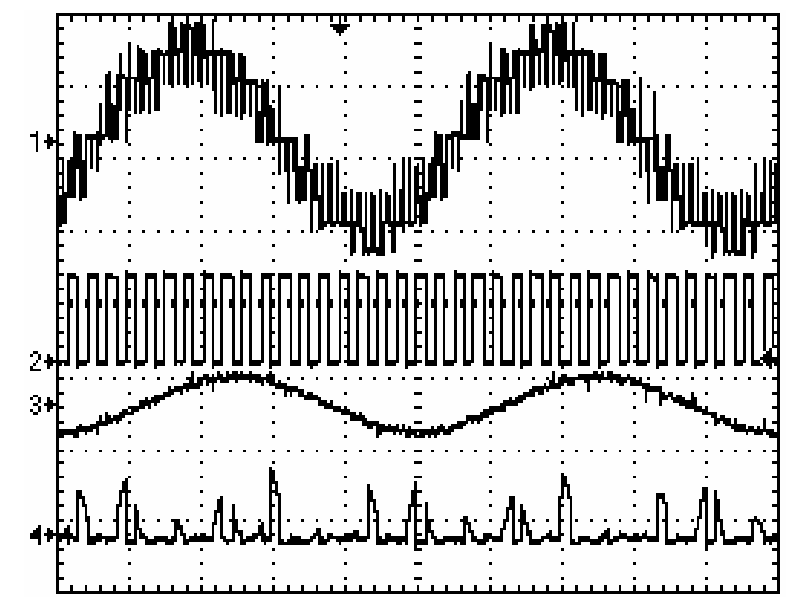

Fig. 7(c) Top trace is phase voltage, second trace is voltage across the input switch, third trace is phase current and bottom trace is Switch current at $\mathrm{M}=0.8$. [X-axis $5 \mathrm{~ms} / \mathrm{div}, \mathrm{Y}$-axis $50 \mathrm{~V} / \mathrm{div}, 1 \mathrm{~A} / \mathrm{div}$ (third trace) and $2 \mathrm{~A} / \operatorname{div}($ fourth trace)].

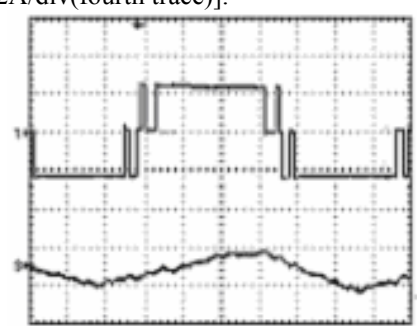

(a)

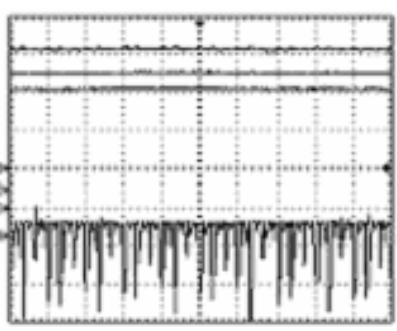

(b)
Fig.8(a) Top trace is pole voltage and bottom trace is phase current at $\mathrm{M}=1.15$ [ X-axis $2.5 \mathrm{~ms} / \mathrm{div} \mathrm{Y}$-axis $50 \mathrm{~V} / \mathrm{div}$ and $1 \mathrm{~A} / \mathrm{div}$ ]. (b) Top three traces are capacitor voltages and bottom trace is switch $\left(\mathrm{S}_{1}\right)$ current $[\mathrm{X}$ - axis $10 \mathrm{~ms} / \mathrm{div}$, $\mathrm{Y}$-axis $20 \mathrm{~V} / \mathrm{div}$ and $1 \mathrm{~A} / \mathrm{div}]$

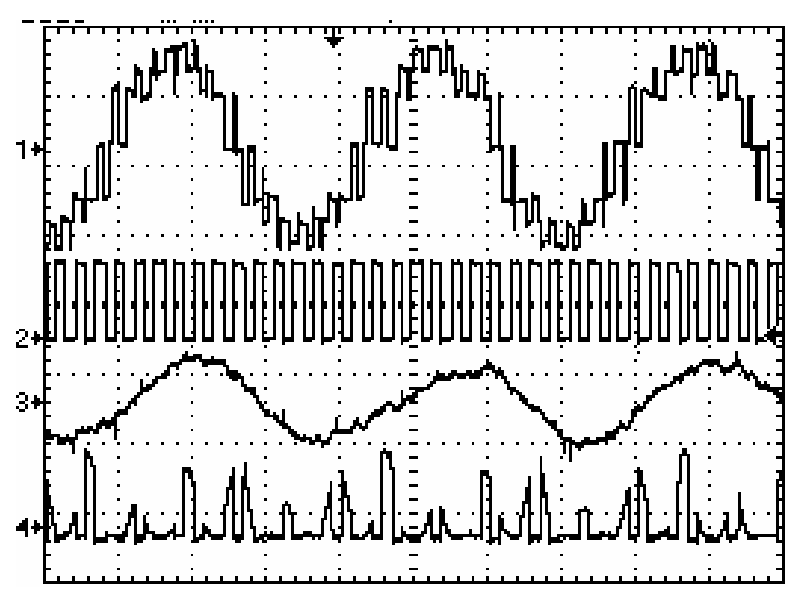

Fig. 8(c) Top trace is phase voltage, second trace is voltage across the switch $\left(\mathrm{S}_{2}\right)$, Third trace is phase current and bottom trace is switch $\left(\mathrm{S}_{1}\right)$ current at $\mathrm{M}=1.15$. [X-axis: $10 \mathrm{~ms} / \mathrm{div}, \mathrm{Y}$-axis: $50 \mathrm{~V} / \mathrm{div}$ and $1 \mathrm{~A} / \mathrm{div}$ (third trace), $2 \mathrm{~A} / \mathrm{div}$ (bottom trace)]
The pole voltage and phase current for modulation index 1.15 (i.e. over modulation) are presented in Fig. 8(a). The capacitor voltages and switch currents are presented in Fig. 8 (b). Fig.8(c) shows the phase voltage, voltage across the switch $\mathrm{S} 1$, phase current and Switch (S1) current. All these experimental results show that the present switched DC link structure can effectively balance the DC link voltage of a conventional NPC inverter with additional conventional twolevel inverter like operation and thereby increase the efficiency and reliability of the drive system in the lower modulation indices. Fig. 9 to Fig. 11 shows the transient performance of the proposed drive topology. Fig.9. shows the phase voltage and phase current when speed command is accelerating from $20 \mathrm{~Hz}$ to $40 \mathrm{~Hz}$ operation. Here the inverter is operated as a NPC three level inverter in the entire period of acceleration. From the oscillograms, it can be observed that in transients the load current increased by 5 to 6 times with very good DC link voltage control.

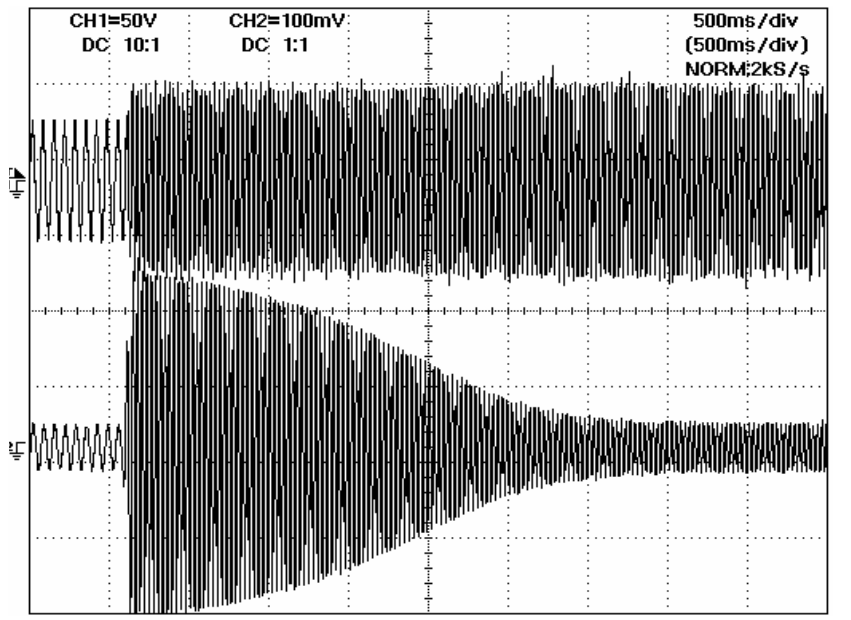

Fig.9.Top trace is phase voltage and bottom trace is phase current during the acceleration from $20 \mathrm{~Hz}$ to $40 \mathrm{~Hz}[\mathrm{X}$-axis $500 \mathrm{~ms} / \mathrm{div}, \mathrm{Y}$-axis $50 \mathrm{~V} / \mathrm{div}$ and $2 \mathrm{~A} / \mathrm{div}]$

Fig. 10 shows the pole voltage and phase current of the inverter when the speed command is accelerating from $15 \mathrm{~Hz}$ to $30 \mathrm{~Hz}$. Here the inverter is operated as a conventional two level inverter in lower modulation indices $(<0.43)$ and as NPC three level inverter in higher modulation indices $(>0.43)$, with sudden acceleration. In Fig. 10 for modulation index from 0.3 to 0.433 , the drive scheme is operated as a conventional two level inverter and from modulation index from 0.43 to 0.6 it is operated as a three level inverter, with correct DC link voltage control

Fig. 11 shows the voltage across the capacitor (C2) and the phase current during the sudden acceleration from $20 \mathrm{~Hz}$ to $40 \mathrm{~Hz}$. 


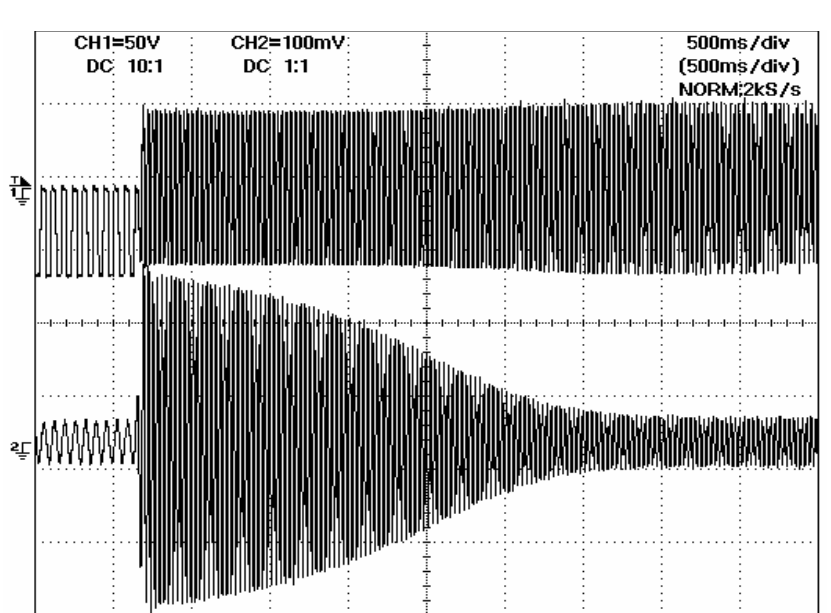

Fig.10. Top trace is pole voltage and bottom trace is phase current during the acceleration form $15 \mathrm{~Hz}$ to $30 \mathrm{~Hz}$ [X-axis $500 \mathrm{~ms} / \mathrm{div}, \mathrm{Y}$-axis $50 \mathrm{~V} / \mathrm{div}$ and 2A/div]

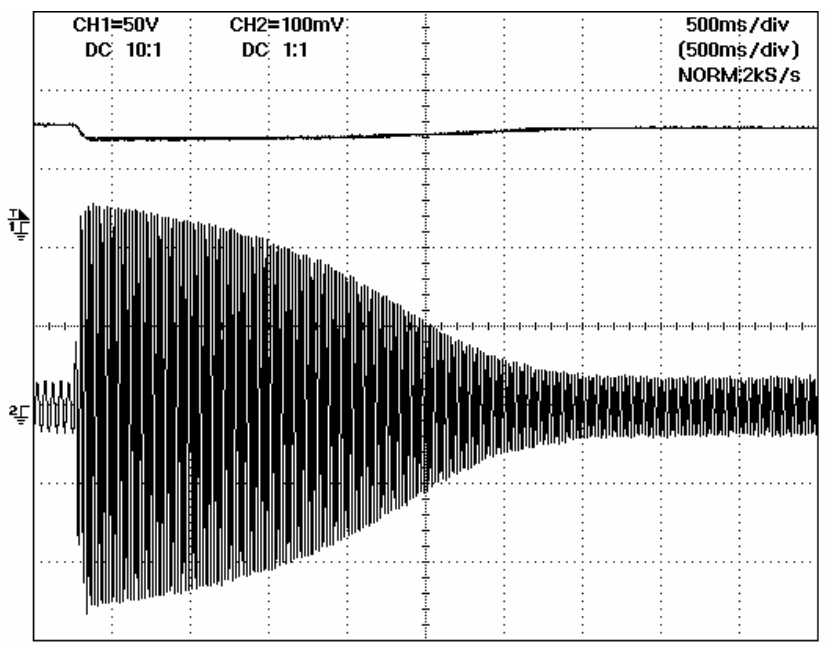

Fig.11. top trace is capacitor voltage and bottom trace is phase curren during the acceleration form $20 \mathrm{~Hz}$ to $40 \mathrm{~Hz}$ [X-axis $500 \mathrm{~ms} / \mathrm{div}, \mathrm{Y}$-axis $50 \mathrm{~V} / \mathrm{div}$ and $2 \mathrm{~A} / \mathrm{div}]$

\section{CONCLUSIONS}

In the proposed topology the voltage fluctuations of the neutral point of a conventional NPC three level inverter fed drive are avoided by switching the voltage source between two capacitors at constant frequency independent of NPC inverter operation. This configuration can be operated as a two level inverter or as a three level inverter in lower modulation indices $(<0.43)$. The voltage fluctuations of neutral point in lower modulation indices can be completely eliminated by operating as a two level inverter.

The DC link Voltage required is half compared to the conventional three level NPC inverter. The voltage rating of all the devices used in proposed topology is equal to the source voltage (i.e. $\mathrm{Vdc} / 2$ ).
This configuration needs only one power supply compared to an H-bridge topology and other cascaded two-level inverters topologies. The proposed switched DC link topology is experimentally verified for the full modulation range, on a $1 \mathrm{KW}$ Induction motor drive, for steady state as well as in the transient operation, with very good control of the DC link voltage. This can also be extended further to diode clamped inverters of level more than three.

\section{REFERENCES}

[1] Nabae, A., Takahashi, I., and Agaki, H: 'A new neutral point- clamped PWM inverter', IEEE Trans. Ind. Appl., 1981, 17, pp. 518-523.

[2] Manjrekar, M.D., and Lipo, T.A.: 'A Hybrid Multilevel Inverter Topology for Drive Applications'. Proceedings of 13th Annual Applied electronics Conference (APEC), California, 15-19 February 1998, pp.523 $-529$.

[3] Rufer, A., Veenstra, M., and Gopakumar, K.: 'Asymmetric multilevel converter for high resolution voltage phasor generation'. Proceedings of 8th European Conference on Power electronics and applications (EPE), Lausanne, 13-16 September 1999, pp. P1-P10.

[4] E.G. Shivakumar, K. Gopakumar, S .K. Sinha, Andrei Pittet, V T.Ranganathan, "space vector pwm control of dual inverter fed Openend winding induction motor drive" APEC 2001, Vol.1., march 2001, pp. 399-405

[5] V.T. Somasckhar, K.Gopakumar, " Threc-lcvel inverter configuration cascading two two-lcvel invertcrs", IEE Proc.- Elcctr. Powcr Appl. Vol. 150, No.3, May 2003, pp.245 - 254.

[6] V.T. Somasekhar, M.R.Baiju and K. Gopakumar, "Dual two-level inverter scheme for an open-end winding induction motor drive with a single DC power supply and improved DC bus utiliszation", IEE Proc.Electr. Power Appl., Vol. 151, No. 2, March 2004. pp. 230 - 238.

[7] Bum-Seok Suh, and Dong-Seok Hyun, "A New -Level High Voltage Inversion System” IEEE Trans. Ind. Elec., Vol. 44, No.1, FEB. 1997, pp. $107-115$.

[8] F. Z. Peng, "A generalized multilevel inverter topology with self voltage balancing," IEEE Trans. Ind. Appl., vol. 37, no. 2, pp. 611-618, Mar./Apr. 2001.

[9] Won-Sik Oh, Sang-Kyoo Han, Seong-Wook Choi, and Gun-Woo Moon, "Three Phase Three-Level PWM Switched Voltage Source Inverter With Zero Neutral Point Potential", IEEE Trans. Power Elec., Vol. 21, No.5, Sept. 2006. pp $1320-1327$.

[10] R.S. Kanchan, M.R. Baiju, K.K. Mohapatra, P.P. Ouseph and K. Gopakumar, "Space vector PWM signal generation for multilevel inverters using only the sampled amplitudes of reference phase voltages", IEE Proc.-Electr. Power Appl., Vol. 152, No.2, April 2005. pp 297 -309.

[11] A.V Jouanne, Shaoan Dai, Haoran Zhang, " A multilevelinverter approach providing DC-Link Balancing, ride through enhancement, and common mode voltage elimination" IEEE Trans. Ind. Elec., Vol. 49, No.4, Aug. 2002, pp. $739-745$.

[12] Sergio Busquets - Monge, Josep Bordonau, Dusahn Boroyevich, and Sergio Somavilla, " The nearest three virtual space vector PWM- A modulation for the comprehensive neutral point balancing in the threelevel NPCinverter" IEEE Powerelectronics letters,vol. 2, NO.1, March 2004,pp.11-15.

[13] Zhiguo Pan, F.Z Peng, Keith A. Corzine,Victor Stefanovich,John M.Leuthen, Slobodan Gataric, " Voltage balancing control of diode clamped multilevel rectifier/ inverter systems" IEEE Trans. Ind. Appl., vol. 41, no. 6, Nov/Dec. 2005,pp.1698-1706.

[14] Joachim Holtz, Nikolaos Oikonomou, “ Neutral point potential balancing algorithm at lower modulation index for three level inverter medium voltage drives", IEEE Trans. Ind. Appl, vol. 43, no. 3, May./Jun. 2007,pp.761-768. 